\title{
A Simple Technique for Rapid Assessment of Rat (Rattus norvegicus) Sperm Motility
}

\author{
Muhammad Ja'far Luthfi ${ }^{1, *}$, Mahanem Mat Noor ${ }^{2}$ \\ ${ }^{1}$ Department of Biological Education, Faculty of Tarbiyah and Education, Universitas Islam Negeri Sunan Kalijaga Yogryakarta, Indonesia \\ ${ }^{2}$ School of Bioscience and Biotechnology, Faculty of Science and Technology, Universiti Kebangsaan Malaysia, Malaysia \\ Corresponding author* \\ jafarluthfi@yahoo.com
}

Manuscript received: 20 September, 2020. Revision accepted: 19 February, 2021. Published: 25 February, 2021.

\begin{abstract}
Assesment of rat sperm motility can be carried out on sperm sample from epididimal source using minimal amount of equipment. This method will aid researcher and practitioner working in the field of sperm quality to determined rat sperm motility rapidly and efficiently.
\end{abstract}

Keywords: sperm quality; sperm motility; rat; haemocytometer.

\section{INTRODUCTION}

Sperm motility is one of the most important parameters determining sperm quality (Martinez et al., 2000; Talarczyk-Desole et al., 2017). The results of sperm motility assessment can be used more directly to address problems affecting male reproductive organs (Björndahl, 2010). The other parameters are sperm count and sperm morphology (Freund \& Carrol 1964). These three components (sperm motility, sperm count, and sperm morphology) compose of sperm quality (Perreault \& Cancel 2001). The most frequently used techniques to assess sperm qualiy are counting chambers (e.g. haemocytometer and Makler chamber). These techniques, however, are subject to a high variability (Yang et al., 2019).

Much effort has been made to speed up the objective measurement of sperm motility. CASA (Computer Aided Sperm Analysis) and IVOS (Integrated Visual Optical System) are automatic methods of sperm quality testing. The techniques, however, need sophisticated equipment not available in many laboratories. They are too technically complex and too expensive for routine use. Manual observation is still the most widely used method for testing sperm motility (Das 1985; Kuster 2005; Macpherson, 2001).

The aim of this study was to determine the optimal manual technique for assessment of rat sperm motility using arbitrary scale. The technique was based on years of practices in our laboratories. It provides a practical and simple means for assessment of rat sperm motility for the purpose of determining the fertility status the animal.

\section{MATERIALS AND METHODS}

\section{Equipments and Materials}

The equipment needed in the analysis of rat sperm motility were as follows: a light microscope, micropipette, petri dishes, Improved Neubauer Haemocytometer, $\mathrm{CO}_{2}$ incubator, small animal surgical instruments, and hand counter.

The materials needed in the analysis of rat sperm motility were as follows: three adult male SpragueDawley rats (Rattus norvegicus), Biggers, Whitten, \& Whittingham (BWW) medium, and cover glasses. The study was done in the Zoology Laboratory of University Kebangsaan Malaysia and the Zoology Laboratory of UIN Sunan Kalijaga Yogyakarta.

\section{Preparation of Sperm Suspension}

Sperm samples were taken from the left cauda epididymis. The cauda epididymis was separated based on the epididymal division by Hamilton (1975), then placed in a petri dish, minced and incubated in $15 \mathrm{~mL}$ of Biggers, Whitten \& Whittingham (BWW) media solution (Biggers et al. 1971) for 30 minutes in $37^{\circ} \mathrm{C}$ in an incubator of $5 \% \mathrm{CO}_{2}$ to let sperm swim in the media (swim-up technique) (Luthfi, 2015; Luthfi \& Noor, 2015).

\section{Procedure for Assessing Sperm Motility}

Sperm motility were determined using Improve Neubauer Haemocytometer as described previously (Prasad et al., 1972; WHO, 1999) with modification. The cover glass was attached firmly to the Improved Neubauer Haemocytometer counting grid area. The interference pattern (> 10 newton's rings/fringes) should be seen between the glass surfaces of the two areas 
where the glass cover is attached to the haemocytometer. The line/newton's rings that appear too few indicate that the distance between the cover glass and the haemocytometer is widened, therefore the counting chamber volume becomes larger and the assessment would be incorrect. The center of the haemocytometer counting grid area is different from the other ones because it consists of 25 larger squares bounded by triple lines each, while the ones in the corners consist of 16 larger squares. In addition, the larger squares inside the central counting grid are subdivided into 16 even smaller squares each (Figure 1).

A total of $10 \mu \mathrm{L}$ of sperm suspension from the preparation of sperm samples were taken with a micropipette, then inserted into the space between the cover glass and the haemocytometer in one of its counting chamber. The other counting chamber was also filled in the same way. Let the sperm settled in the chambers for 5 minutes. Each counting chamber must be filled correctly. The suspension was inserted slowly to let the liquid evenly distributed by capillary force. If the filling on to the counting chamber was uneven, wipe the slide and then the process of filling the chamber must be repeat. The removal of excessive volume from the counting chamber must not be done because it will change the density of sperm in the counting chamber.

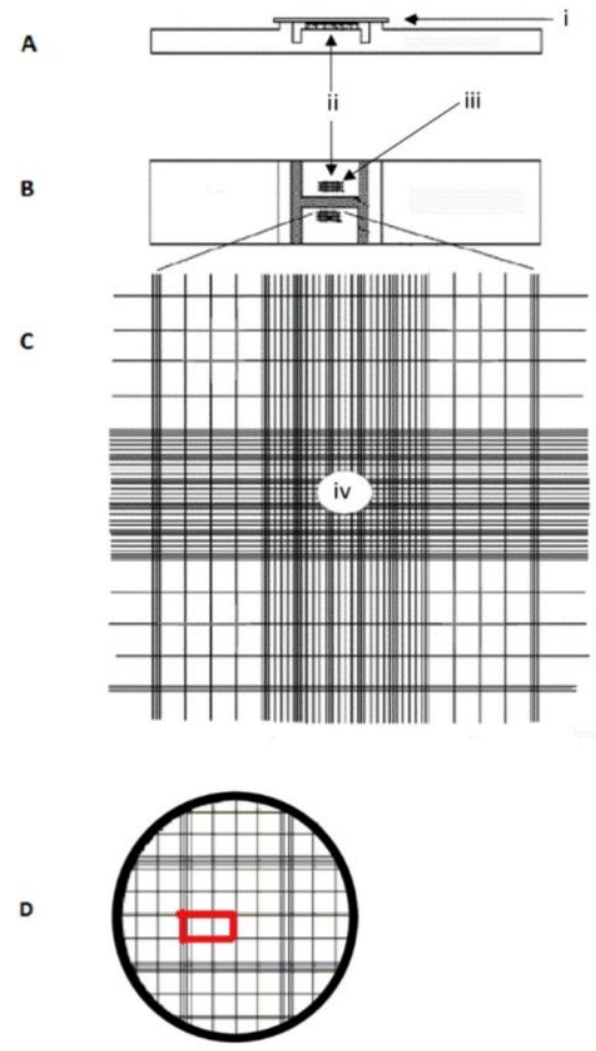

Figure 1. Haemocytometer. A. Side view. B. Top view. C. One of the two haemocytometer counting chambers. D. Insert of iv. Legend: i. Cover glass; ii. Counting chamber; iii. Counting grid area; iv. One of the 25 larger squares.
After both counting chambers were filled, assessment of sperm motility was carried out. The sperm motility was observed at 200x or 400x magnification using a light microscope. Systematically scan the center of the haemocytometer counting grid area, started with the uppermost left square of the 25 large squares, continued to the next three squares to the right, and the squares at the row below, and so on. Assessment were done only for intact sperm (defined as having a head and a tail). Approximately 100 sperm in each counting chamber were assigned to minimize deviation. Sperm motility is estimated to follow the criteria as defined by WHO $(1999 ; 2010)$ and is denoted by the letters a, b, c (from the fastest to the slowest) as follows:

a: progressive motility; $\geq 25 \mu \mathrm{m} / \mathrm{s}$ where $25 \mu \mathrm{m}$ is the same as the length of 2 squares (smallest square) of the haemocytometer (see red rectangle in figure 1D) b: non-progressive motility; $<5 \mu \mathrm{m} / \mathrm{s}$

c: no motility

\section{RESULT AND DISCUSSION}

Determination of sperm motility is an important step in the analysis of sperm quality. However, there are various methods of assessing sperm motility in terms of equipment, technicality and practicality. Different laboratories use different methods. This study was use haemocytometer to determine sperm motility. The determination of the method is mostly based on the practice and experience of testing rat sperm samples carried out at the Zoology Laboratory of the Faculty of Science and Technology, UIN Sunan Kalijaga and Zoology Laboratory of University Kebangsaan Malaysia (data not shown).

The sperm motility of the laboratory animals can be determined from ejaculate or epididymal samples. The determination of epididymal sperm motility is using only sperm from the caudal part (Clegg et al., 2001). Changes in the progression/rate of sperm motility after substance or drug treatment can provide important clues as to the effect of a substance on sperm fertilizing capacity (Working, 1988).

Motility pattern is one of the most important and simplest variables in determining the fertility potential of sperm because immotile sperm will not be able to penetrate the mucus layer of the cervix to reach the ovum and fertilization to occur. Sperm motility patterns is an important factor in fertilization, as a strong swing of the sperm tail is necessary for the sperm head to penetrate the lining of the ovum (Partodihardjo, 1992). Progressive motility is a normal sperm movement. Circular motion and reversion movements are often signs of cold shock or due to abnormal sperm morphology. Meanwhile, wavy motion and vibrating motion occur more frequently in old men (Atherton, 1977). 
Sperm motility is observed with either physiological saline or other nutrient medium. Sperm were observed under a microscope slide with/without a cover glass or with a capillary tube. CASA (Computer Aided Sperm Analysis) and IVOS (Integrated Visual Optical System) are automatic objective methods for testing sperm motility. However, manual observation is still the most widely used method for testing sperm motility using an arbitrary scale (Das 1985; Kuster 2005; Strader 1996).

This study revealed that using this method, 25-45 percent of rat sperm would fall into category of progresssive motility, 45-65 percent were of nonprogressive motility category, and 15-35 were of no motility category. Aproximately, those numbers could be used as a reference for normal sperm motility of rat sperm. Several things need to be considered in order to achieve consistency in using this method. First, we must ensure that the cutting of cauda epididymis was done consistently in every replication. Second, micropipette insertion of samples in each counting chamber must be perfect. Third, the room temperature used in determining the sperm motility must be the same for all sperm sample assessed. Fourth, the time needed to assess the sperm motility should consistent from slide to slide. All these things affect the consistency of the sperm motility assesment. The procedures that are followed strictly will ensure the accuracy of the assessment.

\section{CONCLUSION}

Using this method, researchers can determine the rat sperm motility in a practical way. Most of the materials and equipments used in this method are widely available. The increasing importance of sperm motility analysis will be consistent with the adoption and development of this simple and rapid method.

Conflict of interest: The author declares that there are no conflicts of interest concerning the publication of this article.

\section{REFERENCES}

Atherton, R.W. 1977. Evaluation of sperm motility in Hafez, E.S.E. (ed). Techniques of Human Andrology. 175-179. Elsevier. Amsterdam.

Biggers, J.D., Whitten, W.K. \&Whittingham, D. 1971. The culture of mouse embryos in vitro in Daniel, J.C. (ed). Methods in Mammalian Embryology. 86-116. Freeman, San Francisco, CA.

Björndahl, L. 2010. The usefulness and significance of assessing rapidly progressive spermatozoa. Asian J Androl. 2010 12(1): 33-35.

Clegg, E.D., Perreault, S.D. \& Klinefelter, G.R. 2001. Assesment of male reproductive toxicity in Hayes, A.W. (ed). Principles and methods of toxicology. 1264-1292. Fourth editions. Taylor \& Francis. Philadelphia.
Das, R. P. 1985. Assessment of spermatozoal function. J. Biosci. 7 (2): 245-255.

Freund, M. \& Carol, B. 1964. Factors affecting haemocytometer counts of sperm concentration in human semen. Journal of Reproduction and Fertility 8: 149-155.

Hamilton, D.W. 1975. Structure, function of the epithelium lining the ductuli efferents, ductus epididymis and ductus deferens in the rat in Hamilton, D.W. \& Greep, R.O. (eds). Handbook of Physiology, Section VII, Endocrinology, vol.5, Male Reproductive System. 259-301. American Physiological Society, Washington D.C.

Kuster, C. 2005. Sperm concentration determination between hemacytometric and CASA systems: Why they can be different. Theriogenology 64: 614-617.

Luthfi, M.J. 2015. A simple and practical method for rat sperm epididymal sperm count (Rattus norvegicus). Biology, Medicine \& Natural Product Chemistry 4 (1): 1-3.

Luthfi, M.J., Noor, M.M. 2015. Analisis Kualitas Sperma Tikus Percobaan (Jumlah, Motilitas, dan Morfologi). UNS Press. Surakarta. Indonesia.

Macpherson, M.L. 2001. How to Evaluate Semen in the Field. Proceedings of the Annual Convention of the AAEP. Volume 47. USA.

Martínez, C., Mar, C., Azcárate, M., Pascual, P., Aritzeta, J.M., López-Urrutia, A. 2000. Sperm motility index: a quick screening parameter from sperm quality analyser-IIB to rule out oligo- and asthenozoospermia in male fertility study. Human Reproduction 15 (8): 1727-1733.

Partodihardjo, S. 1992. Ilmu reproduksi hewan. Cetakan ke-3. 2537. Penerbit Mutiara Sumber Widya. Jakarta.

Perreault, S.D. \& Cancel, A. M. 2001. Significance of incorporating measures of sperm production and function into rat toxicology studies. Reproduction 121: 207-216.

Prasad, M.R.N., Chinoy, N. J., Kadam. K.M. 1972. Changes in succinic dehydrogenase levels in the rat epididymis under normal and altered physiologic conditions. Fertility and Sterility 23 (3): 186-190.

Strader, L.F., Linder, R. E. \& Perreault. S.D. 1996. Comparison of rat epididymal sperm counts by IVOS HTM-IDENT and hemocytometer. Reproductive Toxicology 10 (6): 529-533.

Talarczyk-Desole, J., Anna Berger, A., Taszarek-Hauke1, G., Jan Hauke, J., Pawelczyk, L., Jedrzejczak, P. 2017. Manual vs. computer-assisted sperm analysis: can CASA replace manual assessment of human semen in clinical practice? Ginekologia Polska 88 (2): 56-60.

White, W.J. 2001. The use of laboratory animals in toxicologic research in Hayes A.W. (ed). Principles and Methods of Toxicology. Fourth Edition. 773-775. Taylor \& Francis. Philadelphia.

WHO. 1999. Laboratory manual for the examination of human semen and semen-cervical mucus interaction. New York: Cambridge University Press.

WHO. 2010. WHO laboratory manual for theExamination and processing of human semen. Fifth Edition. WHO Press. Geneva, Switzerland.

Working, P.K. 1988. Male Reproductive Toxicology: Comparison of the Human to Animal Models. Environmental Health Perspectives 77: 37-44.

Yang, Y., Zhang, Y., Ding, J. 2019. Optimal analysis conditions for sperm motility parameters with a CASA system in a passerine bird, Passer montanus. Avian Res 10 (35) https://doi.org/10.1186/s40657-019-0174-5 
THIS PAGE INTENTIONALLY LEFT BLANK 